\title{
Treatment of inborn errors of metabolism
}

\author{
Ida Vanessa Schwartz, ${ }^{1}$ Carolina Fischinger Moura de Souza, ${ }^{2}$ \\ Roberto Giugliani ${ }^{3}$
}

\begin{abstract}
Objective: To describe the current state of treatment for disorders of intermediate metabolism (primarily of amino acids, urea cycle and organic acids) and for diseases related to two subcellular organelles (lysosomes and peroxisomes).

Sources: In covering the treatment of disorders of intermediate metabolism, priority was given to the most important methods for managing intoxication, in view of the importance for pediatricians to treat acute and life-threatening cases. The article also provides a general overview of the treatment for lysosomal and peroxisomal diseases, with emphasis on enzyme replacement therapy, which is a treatment modality that is growing in use and with which pediatricians should make themselves familiar.
\end{abstract}

Summary of the findings: The most important measures used to manage the intoxication present in many inborn errors of intermediate metabolism were presented (restriction of substrate build-up by means of diet or enzymatic inhibition, removal of toxic products, stimulation of residual enzyme activity, replacement of the deficient product). The section on treatment for lysosomal and peroxisomal diseases includes tables providing information on the treatments available.

Conclusions: Treating inborn errors of metabolism is a complex task that should be performed by a multidisciplinary team of which the pediatrician is the key member. This article provides practical information relating to the management of some inborn errors of metabolism and provides pediatricians with a general overview of recent developments in this area of medicine.

J Pediatr (Rio J). 2008;84(4 Suppl):S8-19: Treatment, genetic diseases, inborn errors of metabolism, dietary management, enzyme replacement therapy.

\section{Background}

Treatment of genetic diseases is a field of medicine that has seen significant advances over recent decades. An understanding of the pathophysiology of the majority of these conditions has made it possible to define metabolic management protocols that are able to minimize or even avert the clinical manifestations of many inborn errors of metabolism (IEM). This process began with disorders of intermediate metabolism, but over recent years spectacular progress has also been made with IEM that involve larger molecules and subcellular organelles, as is the case of lysosomal diseases. In these cases, advances in biotechnology have not only made it possible to interfere with the synthesis of these molecules, but also to produce in laboratories the actual enzymes that are deficient in order to administer them to patients. Furthermore, there are new strategies in permanent development, involving, for example, recovery of residual enzyme activity using chaperones, cell therapy and gene therapy and also combination treatments.

This article focuses on those themes that we expect to be of greatest interest to pediatricians: management of intermediate IEM that cause "acute intoxication" and in which appropriate treatment in good time can very often save a life and even avoid sequelae; and the state of the art in terms of the newest treatments for storage diseases, involving innovative treatments, the majority of which are already available, but whose high cost has restricted access, prompting intense discussion.

1. Doutora. Professora adjunta, Departamento de Genética, Universidade Federal do Rio Grande do Sul (UFRGS), Porto Alegre, RS, Brazil.

2. Doutora. Serviço de Genética Médica, Hospital de Clínicas de Porto Alegre (HCPA), Porto Alegre, RS, Brazil.

3. Doutor. Professor titular, Departamento de Genética, UFRGS, Porto Alegre, RS, Brazil.

No conflicts of interest declared concerning the publication of this article.

Suggested citation: Schwartz IV, de Souza CF, Giugliani R. Treatment of inborn errors of metabolism. J Pediatr (Rio J). 2008;84(4 Suppl):S8-19.

doi:10.2223/JPED.1801 


\section{Treatment of intermediate IEM}

The significant progress that has been made in understanding the biochemical and molecular bases of intermediate IEM has paved the way for an ever growing arsenal of therapeutic options for the management of these conditions. Although for some diseases treatment possibilities are still restricted, either because knowledge of the basic defect is still lacking or because it has not proved possible to intervene in its course, this has been the area of genetics that has most benefited from new biotechnology tools which, together with older, but effective, techniques of special diets and cofactor supplementation, have meant that nowadays many IEM are treatable conditions.

In parallel, the development of more sophisticated and sensitive diagnostic methods, very often incorporated into neonatal screening programs, has made earlier and more precise diagnoses possible, often before symptoms of the disease manifest. This is particularly important to remember, since very often the occurrence of neurological damage is related to the duration and period of exposure to toxic metabolites. Therefore, correct intervention immediately after diagnosis is, in many cases, a fundamental determinant of prognosis in these cases.

In this article we will review the current status of IEM treatment with the intention of providing pediatricians with a practical and up-to-date overview of the therapeutic management of these situations.

\section{General principles of treating IEM that present with manifestations of "intoxication"}

This group includes intermediate IEM provoked by acute and/or progressive intoxication caused by accumulation of a toxic substrate resulting from blockage of intermediate metabolism pathways. The principal disorders in this group are the aminoacidopathies (phenylketonuria, maple syrup urine disease [MSUD], homocystinuria, tirosinemias, and others), the organic acidemias (methylmalonic, propionic and isovaleric acidemias, and others), urea cycle defects (ornithine transcarbamylase deficiency, for example), sugar intolerance (galactosemia, hereditary fructose intolerance), and metal intoxication (Wilson's disease, hemochromatosis, etc.). All of these conditions exhibit a certain similarity in terms of clinical manifestations: they do not compromise embryonic or fetal growth, patients have an interval after birth of variable duration free from symptoms before the signs and symptoms of "intoxication" manifest, whether in an acute manner (vomiting, coma, liver failure, thromboembolic complications) or chronically (growth and development deficits, visual disorders, cardiomyopathy, psychiatric symptoms). Symptoms may be triggered by changes to the catabolic state (fever, viral infections or reduced food intake). Early recognition of this group of pathologies is of fundamental importance since, for the majority of them, there are treatment options, whether with supplementation of certain vitamins or dietary changes. In the majority of cases, if treatment is instituted early enough, clinical status can be reversed, promoting normal development with minimal or even absent sequelae. ${ }^{1}$

The primary treatment objective with these conditions is to reestablish metabolic balance and, to achieve this, a range of strategies can be used either individually or in combination. Below, we will describe certain general principles of the treatment for this group of IEM and specific management for certain metabolic diseases.

\section{Restricting substrate accumulation by means of diet}

Since the 1950s, when it was discovered that phenylketonuria could be treated by restricting the quantity of phenylalanine in the diet, there have been great advances in treatment for other amino acid and organic acid metabolism diseases. In MSUD there are increases in the levels of leucine, isoleucine and valine in circulation and in homocystinuria there are increases in homocysteine and methionine. Both are examples of aminoacidopathies in which the levels of toxic products can be restricted and controlled with specific diets. Nevertheless, for other pathologies, such as organic acidemias and certain urea cycle defects, although restricting protein intake can reduce the accumulation of toxic metabolites, neither the biochemical nor the clinical results are always favorable since there is accumulation of intermediate substrates which continue to be produced even after institution of the diet. ${ }^{2}$ Additionally, it should be borne in mind that treatment must be continued for life, even after stabilization of symptoms. This has stimulated the development of foods designed for prolonged treatment of patients with metabolic diseases. The cost of these foods is elevated and their flavors, despite continuous improvements, remain different from a normal diet. ${ }^{3}$

Classical galactosemia is caused by a deficiency of the galactose-1-phosphate uridyltransferase (GALT) enzyme and is already manifest in the neonatal period, triggered by galactose intake, generally from breastmilk, leading to cholestatic jaundice, liver failure, food intolerance, renal tubular dysfunction, sepsis and cataracts. The acute and hepatic forms can be rapidly reversed by the introduction of a diet free from lactose and galactose. However, studies have demonstrated that dietary restrictions do not avert the long term complications such as psychomotor development delays, verbal dyspraxia, motor abnormalities and hypogonadotropic hypogonadism, possibly as a result of endogenous galactose production, which is independent of restricted dietary intake. ${ }^{4}$

Another example of application of a dietary strategy is supplementation with zinc for Wilson's disease because it aids with reducing the amount of copper absorbed by the intestine, competing for the same transport protein. ${ }^{5}$

Table 1 lists some IEM that can benefit from dietary therapy and provides an indication of efficacy. 
Table 1 - Inborn errors of metabolism that respond to dietary therapy

\begin{tabular}{|c|c|c|c|}
\hline Disease & Defect & Treatment & Efficacy* \\
\hline \multicolumn{4}{|l|}{ Aminoacidopathies } \\
\hline Phenylketonuria & $\begin{array}{l}\text { Phenylalanine } \\
\text { hydroxylase }\end{array}$ & Restriction of phenylalanine intake & +++++ \\
\hline Maple syrup urine disease & $\begin{array}{l}\text { Branched chain } \\
\text { alpha-keto acid } \\
\text { dehydrogenase }\end{array}$ & $\begin{array}{l}\text { Restriction of leucine, isoleucine } \\
\text { and valine intake }\end{array}$ & ++++ \\
\hline Homocystinuria & Cystathionine- $\beta$-synthase & $\begin{array}{l}\text { Restriction of methionine, } \\
\text { supplementation with vitamin B6 } \\
\text { and betaine }\end{array}$ & ++++ \\
\hline Tyrosinemia & Fumarylacetoacetase & $\begin{array}{l}\text { Restriction of phenylalanine and } \\
\text { tyrosine, supplementary } \\
\text { administration of NTBC }\end{array}$ & ++ \\
\hline \multicolumn{4}{|l|}{ Organic acidemias } \\
\hline Aciduria type 1 & $\begin{array}{c}\text { Glutaryl-CoA } \\
\text { dehydrogenase }\end{array}$ & $\begin{array}{l}\text { Restriction of lysine and } \\
\text { tryptophan, supplementation with } \\
\text { L-carnitine }\end{array}$ & +++ \\
\hline Propionic and methylmalonic aciduria & $\begin{array}{c}\text { Propionyl-CoA } \\
\text { carboxylase and } \\
\text { methylmalonyl-CoA } \\
\text { carboxylase }\end{array}$ & $\begin{array}{l}\text { Restriction of isoleucine, valine, } \\
\text { methionine, threonine, } \\
\text { supplementation with L- carnitine }\end{array}$ & ++ \\
\hline \multicolumn{4}{|l|}{ Diseases of the urea cycle } \\
\hline OTC deficiency & $\begin{array}{c}\text { Ornithine } \\
\text { transcarbamylase }\end{array}$ & Restriction of arginine & +++ \\
\hline Others & Several different enzymes & Restriction of protein & + \\
\hline \multicolumn{4}{|l|}{ Carbohydrate metabolism diseases } \\
\hline Galactosemia & GALT & $\begin{array}{l}\text { Restriction of lactose and } \\
\text { galactose }\end{array}$ & $\begin{array}{c}++++ \text { (liver, kidneys and } \\
\text { eyes }) \\
+ \text { (brain and ovary } \\
\text { function) }\end{array}$ \\
\hline Hereditary fructose intolerance & $\begin{array}{c}\text { Fructose-1-phosphate } \\
\text { aldolase }\end{array}$ & Restriction of fructose & +++++ \\
\hline
\end{tabular}

GALT = galactose-1-phosphate uridyltransferase; NTBC = 2-(2-nitro-4-trifluoromethylbenzoyl)-1,3-cyclohexanedione; OTC = ornithine transcarbamylase.

$*+=$ minimal efficacy $;+++++=$ maximum efficacy

Adapted from Walter \& Wraith. ${ }^{6}$

Removal of accumulated substrates by enzymatic inhibition

In hereditary or type 1 tyrosinemia, in addition to dietary treatment by restricting tyrosine and phenylalanine, the introduction of 2-(2-nitro-4-trifluoromethylbenzoyl)-1,3- cyclo- hexanedione (NTBC) is a solid advance in treatment of the condition. This drug reduces production of fumarylacetoacetate, maleylacetoacetate and succinylacetone by means of inhibition of the enzyme 4-hydroxyphenylpyruvate dioxygenase. Reducing the levels of these toxic compounds that build 


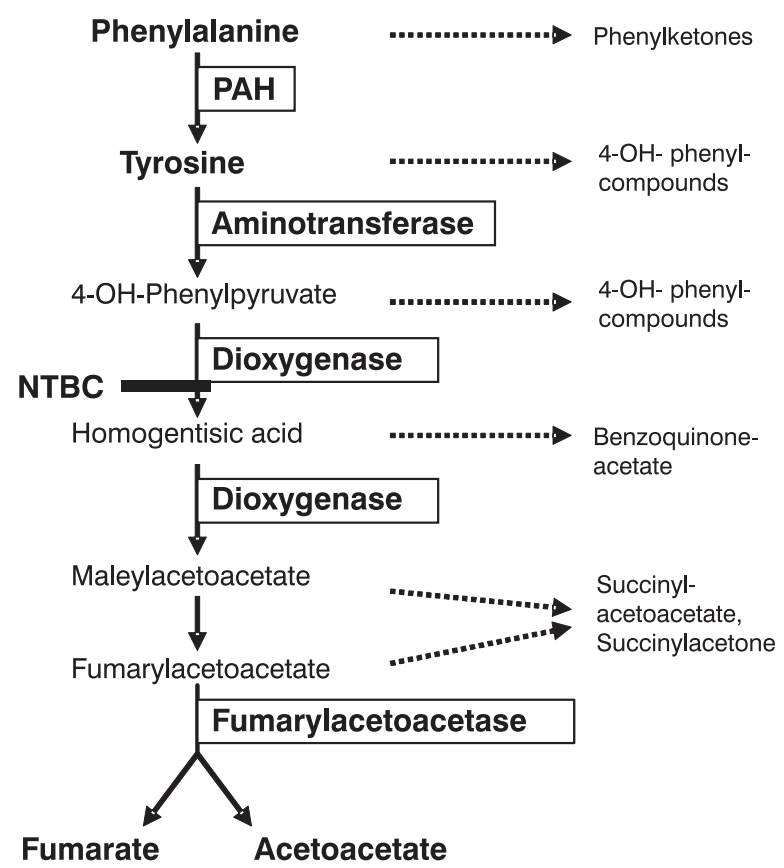

NTBC = 2-(2-nitro-4-trifluoromethylbenzoyl)-1.3-cyclohexanedione; PAH $=$ phenylalanine hydroxylase.

Figure 1 - Metabolism of phenylalanine and tyrosine. A deficiency of the enzyme phenylalanine hydroxylase or the cofactor tetrahydrobiopterin (BH4) causes a buildup of phenylalanine. Deficiency of the enzyme fumarylacetoacetate causes accumulation of fumarylacetoacetate and succinylacetoacetate and acetone. Hydroxyphenylpyruvate dioxygenase is inhibited by NTBC

up as a result of the fumarylacetoacetate deficiency (Figure 1 ), the basic defect in this disease, averts hepatic complications such as cirrhosis and hepatocarcinoma. ${ }^{7}$

\section{Rapid removal of the toxic substrate}

With urea cycle defects and organic acidemias and/or aminoacidopathies, branched chain amino acids are accumulated (leucine, isoleucine and valine) and very often it is not possible to wait for the levels of these toxic compounds to reduce in response to diet, making it necessary to force their removal in order to avoid/minimize related neurological damage. In order to achieve this, depending on the severity of the condition, the toxin can be removed directly (dialysis, for example) or medication can be administered to divert the metabolic pathway or to provoke rapid excretion in urine.

Although hemodialysis or hemofiltration continue to be the most rapid and effective methods for removing toxic metabolites, particularly ammonia, these procedures are technically challenging with neonates. In these cases peritoneal dialysis is the method of choice since it is more practical for use in a neonatal intensive care unit, but the risk of sepsis must always be borne in mind. ${ }^{8}$

The use of sodium benzoate, phenylacetate or sodium phenylbutyrate with urea cycle defects promotes increased excretion of nitrogenated compounds, thereby reducing the accumulation of ammonia.

Although there are no rigorously conducted clinical trials that demonstrate the efficacy of L-carnitine, it has proven its efficacy for the treatment of certain organic acidemias and also of diseases that affect mitochondrial metabolism. The administration of L-carnitine has two main functions: the first is to promote formation of organic acylcarnitines that will reestablish the coenzyme A levels that are important for mitochondrial metabolism and are consumed heavily as a result of the accumulation of organic acids in circulation; the second is to bind to free organic acids so that they can be filtered and excreted effectively by the kidneys. ${ }^{9}$ The effect of carnitine supplementation on diseases that affect its transport is dramatic, with recovery from the cardiomyopathy and prevention of further episodes of hypoketotic hypoglycemia. ${ }^{6}$

Specifically with relation to the treatment of isovaleric aciduria, the use of high doses of glycine leads to the formation of isovalerylglycine, which is rapidly excreted by the kidneys, thereby reducing the high levels of toxic product.

\section{Stimulation of residual enzyme activity}

The catalytic properties of some enzymes are dependent on the participation of compounds that are not proteins, such as vitamins or minerals, which act as cofactors in many metabolic pathways. In patients with biotinidase deficiency, treatment with biotin, a cofactor that is fundamental to the activity of four carboxylases (acetyl-CoA carboxylase, propionyl-CoA carboxylase, pyruvate carboxylase and 3-methylcrotonyl-CoA carboxylase), provokes a dramatic clinical response, reversing the convulsions, metabolic acidosis and cutaneous manifestations. Another example is the use of vitamin B12 for patients with methylmalonic acidemia due to a deficiency of the cobalamin-dependent mitochondrial enzyme (methylmalonyl-CoA mutase), which results in an important response to treatment with reversal of the clinical manifestations of organic acidemia. ${ }^{10}$ It is also known that approximately $50 \%$ of homocystinuria cases due to cystathionine $\beta$-synthase deficiencies respond to treatment with large quantities of pyridoxine (vitamin B6), which provokes increased enzyme activity and reduces serum homocysteine and, as a consequence, reduces ischemic events and ophthalmological damage related to the condition (Table 2). ${ }^{11}$ Long-term use of vitamins (coenzymes) should be restricted to patients who have metabolic errors that are known to respond to treatment. It is also important to comment on the use of a vitamin cocktail for acutely ill patients, generally neonates, where there is a clinical suspicion of an IEM, but no diagnosis has yet been confirmed (Table 3 ). This measure is indicated for cases in which a long time will be needed for diagnostic workup, which in turn could lead to deterioration of the patient's condition. ${ }^{6}$ 
Table 2 - Examples of inborn errors of metabolism that respond to treatment with cofactors

\begin{tabular}{|c|c|c|c|}
\hline Disease & Cofactors & Dose & Variants that respond to treatment \\
\hline Glutaric aciduria type I & Riboflavin & $20-40 \mathrm{mg} / \mathrm{day}$ & Rare \\
\hline Methylmalonic aciduria (CbIA and CbIB) & H hydroxycobalamine (B12) & $1 \mathrm{mg}$ intramuscular/week & Some \\
\hline Propionic aciduria & Biotin & $5-10 \mathrm{mg} / \mathrm{day}$ & Rare \\
\hline Vitamin B6 responsive convulsions & Pyridoxine (B6) & $5-10 \mathrm{mg} / \mathrm{kg} /$ day & All \\
\hline Holocarboxylase synthetase & Biotin & $5-10 \mathrm{mg} / \mathrm{kg} / \mathrm{day}$ & Majority \\
\hline Biotinidase deficiency & Biotin & $5-10 \mathrm{mg} /$ day & All \\
\hline Maple syrup urine disease & Thiamin & $10-50 \mathrm{mg} /$ day & Rare \\
\hline Urea cycle defects & Pyridoxine & $300-600 \mathrm{mg} / \mathrm{day}$ & Rare \\
\hline Classical homocystinuria & Pyridoxine (B6) & $50-500 \mathrm{mg} / \mathrm{day}$ & $50 \%$ \\
\hline
\end{tabular}

Table 3 - Recommended vitamin "cocktail"

\begin{tabular}{|c|c|c|}
\hline Vitamin & Dose & Route \\
\hline Biotin & $10 \mathrm{mg} /$ day & Oral \\
\hline Thiamin & 200 mg/day & Oral \\
\hline Lipoic acid & 100 mg/day & Oral \\
\hline L-carnitine & $25 \mathrm{mg} / \mathrm{kg}$ every $6 \mathrm{~h}$ & Oral or intravenous \\
\hline Coenzyme Q10 & $5 \mathrm{mg} / \mathrm{kg} /$ day & Oral \\
\hline Vitamin C & $100 \mathrm{mg} / \mathrm{kg} /$ day & Oral \\
\hline Riboflavin & $100-300 \mathrm{mg} /$ day & Oral \\
\hline Pyridoxine & $50-500 \mathrm{mg} / \mathrm{day}$ & Oral \\
\hline Pyridoxal phosphate & 20 mg/kg/day & Oral \\
\hline Folinic acid & 20 mg/day & Oral \\
\hline
\end{tabular}

Adapted from Walter \& Wraith. ${ }^{6}$

\section{Replacement of a deficient product}

In some IEM the clinical manifestations are not related to accumulation of substrates, but to a missing product. Replacement of such products is used with some urea cycle defects, where replacement of arginine or citrullin can reverse ammonia intoxication; ${ }^{12}$ in glycogenoses, where carbohydrates can reverse hypoglycemia, and in tetrahydrobiopterin $(\mathrm{BH} 4)$ deficiency, where treatment with the neurotransmitters L-dopa and $5-\mathrm{OH}$-tryptophan improve neuropsychomotor development and considerably reduce convulsive crises and the resulting neurological deterioration. Recently, creatine came into use for treating deficiencies of the enzyme guanidinoacetate methyltransferase, (GAMT), reversing hard to control convulsions, dystonias, neurological regression and psychomotor development delays. In this pathology convulsive crises are caused by a reduction in the ratio between creatine and creatine phosphate in the brain. ${ }^{13}$

\section{Practical guide to managing a selection of specific situations}

Faced with the clinical suspicion that an acutely ill child has a metabolic disease, and in the presence of feeding difficulties, lethargy, vomiting, abnormal tonus, cyanosis, convulsions, irritability, metabolic acidosis, hypoglycemia, respiratory alkalosis and coma, we should employ the following conduct: intensive care, workup tests, nutritional restriction, toxin removal and biochemical monitoring, plus additional treatments depending on the biochemical diagnosis arrived at.

Organic acidemias

The term organic acidemia or aciduria refers to a group of disorders that are characterized by the excretion of organic acids in urine and are caused by enzyme deficiencies. Several 
organic acidemias result from disorders in catabolism of branched chain amino acids. These include MSUD, propionic acidemia, isovaleric acidemia, methylmalonic acidemia, glutaric acidemia , non biotin responsive 3-methylcrotonyl-CoA carboxylase deficiency, 3-hydroxy-3-methylglutaryl-CoA (HMG-COA) lyase deficiency, and others. In the majority of cases the clinical symptoms are nonspecific and lead to encephalopathy.

The first step in diagnosing organic acidemias is based on analysis of organic acids in urine using gas chromatography combined with mass spectrometry (GC/MS). Depending on the specific disorder, plasma concentrations of amino acids and a blood acylcarnitine profile can also be of aid to diagnosis.

The initial management of a patient with suspected organic acidemia consists of: ${ }^{14}$

For a patient with decompensation who has not yet been diagnosed:

1) Assisted ventilation;

2) Correction of hydroelectrolytic imbalances;

3) Removal of protein from the diet;

4) Collection of samples;

4.1) Plasma: $1-2 \mathrm{~mL}$ after immediate centrifuging of the blood with heparin. Freeze at $-20^{\circ} \mathrm{C}$;

4.2) Blood: 4-6 drops on filter paper (Guthrie, Whatmenn 3 MM or similar);

4.3) Urine: $10-20 \mathrm{~mL}$, freeze immediately at $-20^{\circ} \mathrm{C}$;

4.4) DNA: $3-10 \mathrm{~mL}$ of whole blood in ethylenediaminetetraacetic acid (EDTA);

4.5) Cerebrospinal fluid: $1 \mathrm{~mL}$ and freeze immediately at $-70{ }^{\circ} \mathrm{C}$;

5) Parenteral administration of saline solution with glucose;

6) Oral or parenteral administration of a high calorie diet (glucose $30 \mathrm{~g} / \mathrm{kg} /$ day, insulin $0.05-0.2 \mathrm{U} / \mathrm{kg} / \mathrm{h}$, lipids $2-4 \mathrm{~g} / \mathrm{kg} /$ day, if fatty acid oxidation disorders have been ruled out)

7) Administration of vitamin cocktail (already mentioned in the text);

8) Gradual reintroduction of protein supply in cases where diagnosis may take a long time. Maintain at 0.5 to 1.0 $\mathrm{g} / \mathrm{prot} / \mathrm{kg} / \mathrm{day}$.

For a patient in a decompensation crisis with a definite diagnosis:

1) Maintenance of supportive measures;

2) Parenteral administration of large quantities of calories in the form of carbohydrates and lipids;

3) Reintroduction of proteins either parenterally or via nasogastric tube (0.5-0.7 g/ kg/day);

4) Maintain L-carnitine a $100 \mathrm{mg} / \mathrm{kg} /$ day in 4 doses);
5) Administration of specific vitamins depending on the pathology identified.

Treatment over the long term:

1) Protein restriction with or without special formulae;

2) Supplementation with amino acids that are not part of the metabolic pathway, vitamins, mineral salts and carnitine;

3) Regular clinical follow-up with a specialized metabolic disorders team and a multidisciplinary team.

Urea cycle defects

The urea cycle is a series of six metabolic reactions that serve to eliminate excess ammonia that builds up as a result of amino acids and other nitrogenated compounds being broken down (Figure 2). Plasma ammonia levels greater than 150 $\mathrm{mmol} / \mathrm{L}$ in neonates and $80 \mathrm{mmol} / \mathrm{L}$ thereafter are defined as hyperammonemia.

Hyperammonemia is a metabolic emergency and the pathology in question must be diagnosed as quickly as possible. Patients with urea cycle defects exhibit feeding difficulties, vomiting, lethargy, irritability, tachypnea, convulsive crises and behavioral changes and may develop acute encephalopathy with coma. A hyperammonemic coma occurs when serum ammonia concentrations are greater than 300 umol/L and is a medical emergency requiring immediate treatment designed to prevent irreversible brain damage.

Treatment of the acute manifestations of urea cycle defects:

1) Secure the airway for mechanical ventilation. Hyperammonemia is generally associated with respiratory alkalosis;

2) Secure venous access: administrate sufficient fluids to maintain normal hemodynamic balance, monitoring the possibility of cerebral edema. An adequate supply of calories should be provided in the form of glucose solution (10-15\%) to limit endogenous catabolism;

3) Reduce intestinal ammonia absorption: administration of lactulose via oral route or in enema, combined with antibiotics (neomycin), reduces the absorption of ammonia by the intestinal lumen;

4) Administration of L-arginine and L- carnitine: if possible intravenously and at dosages of $250-500 \mathrm{mg} / \mathrm{kg} / \mathrm{day}$ and $100 \mathrm{mg} / \mathrm{kg} /$ day, respectively, even if the enzyme defect is unknown;

5) Administration of sodium benzoate or sodium phenylbutyrate: these can be given at doses of $250-500 \mathrm{mg} / \mathrm{kg} /$ day and $250 \mathrm{mg} / \mathrm{kg} /$ day, respectively;

6) Use of dialysis methods: when the measures described above are not satisfactory, dialysis methods are employed (hemofiltration, hemodialysis, peritoneal dialysis);

7) Reintroduction of proteins: once plasma ammonia concentrations have reduced (below 100umol/L), we can 


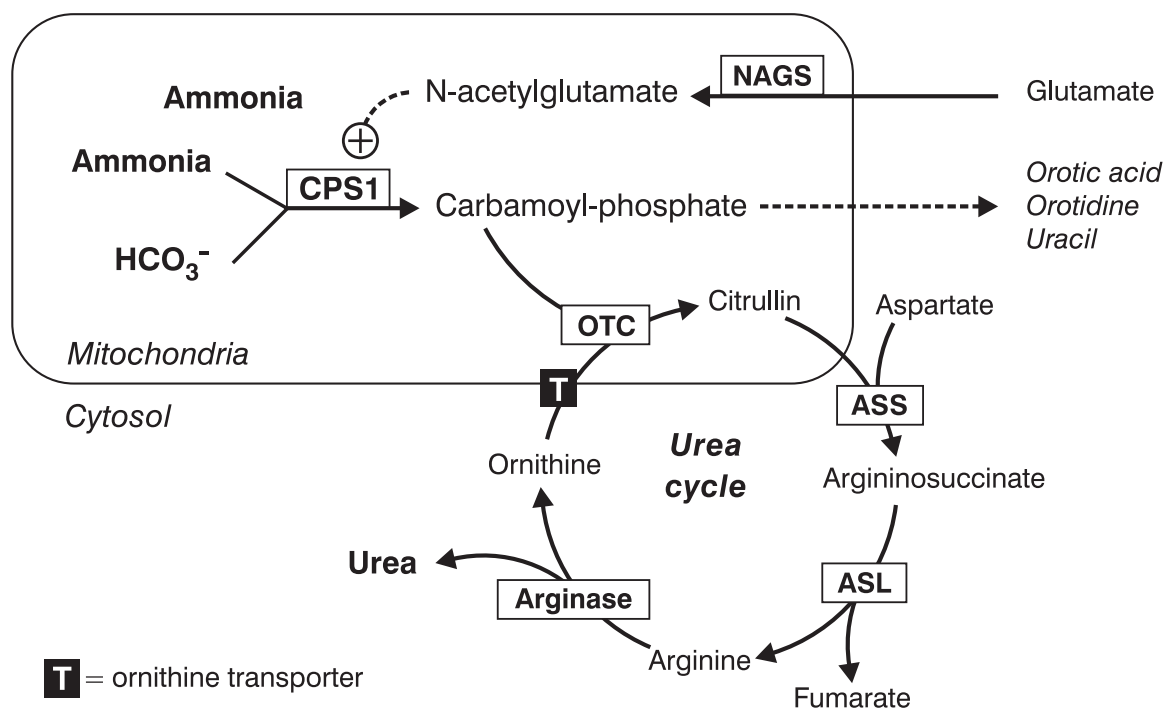

ASL = argininosuccinate lyase; ASS = argininosuccinate synthase; CPS1 = carbamoyl phosphate synthase I; NAGS $=\mathrm{N}$-acetylglutamate synthase; OTC $=$ ornithine transcarbamylase.

Figure 2 - The ammonia (NH3) that is produced by metabolism of amino acids is primarily detoxified by means of conversion to urea in the liver. The enzyme that catalyzes the initial condensation of ammonia with bicarbonate, carbamoyl phosphate synthase I, must be activated by $\mathrm{N}$-acetylglutamate, which is formed by the action of $\mathrm{N}$-acetylglutamate synthase. The carbamoyl phosphate is then bonded to ornithine by transcarbamylase ornithine as a transport molecule. Citrullin is formed, transported out of the mitochondria and bonded to aspartate by argininosuccinate synthase. The resulting argininosuccinate is cleaved by argininosuccinate lyase into fumarate and arginine, which are then hydrolyzed by arginase into ornithine and urea

reintroduce proteins $(0.5 \mathrm{~g} / \mathrm{kg} /$ day $)$ and assess their acceptance, monitoring plasma ammonia levels.

Long-term treatment:

1) The level of protein intake that can be tolerated varies for each patient. Plasma ammonia levels higher than 50 umol/L should be avoided. In summary, excessive protein catabolism should be prevented and an adequate calorie supply provided. However, sufficient quantities of protein should be provided in order to allow adequate growth;

2) with the exception of arginase deficiency patients, all other patients with enzymatic urea cycle deficiencies will require arginine supplementation to maintain plasma levels of this essential amino acid between 50 and 150 umol/L;

3) Continue sodium benzoate or sodium phenylbutyrate. Sodium benzoate conjugates with glycine, forming hippurate, and $1 \mathrm{~mol}$ of nitrogen is excreted for each mol of benzoate administered. The usual dose is $200-300 \mathrm{mg} / \mathrm{kg} /$ day, and in acute situations up to $500-700 \mathrm{mg} / \mathrm{kg} /$ day can be given. The main secondary effects are nausea, vomiting and irritability. The phenylbutyrate combines with glutamine, forming phenylacetylglutamine and eliminating $2 \mathrm{~mol}$ of nitrogen for each mol of phenylbutyrate. The usual dose is $200-600 \mathrm{mg} / \mathrm{kg} /$ day and the main secondary effects are hypokalemia and metabolic alkalosis.
Prognosis will depend on the age of the patient at treatment outset and their response to treatment.

\section{Aminoacidopathies}

Deficiencies of the enzymes involved in the metabolism of amino acids can often result in accumulation of toxic substances with subsequent organ damage. The brain, liver and kidneys are the most often affected organs. The acute symptoms are frequently associated with catabolic states that lead to the breakdown of endogenous proteins and the release of large quantities of amino acids; the clinical characteristics result from the toxicity of the accumulated metabolites, the concomitant deficiency of the product, the importance of the deficient enzyme and the extent of protein intake or liberation of amino acids from protein catabolism. Certain diseases, such as phenylketonuria and homocystinuria, cause chronic neurological damage without acute decompensation. Nevertheless, MSUD, tyrosinemia and nonketotic hyperglycinemia manifest acute symptoms that are very similar to those of the organic acidemias. Depending on the methodology employed, neonatal screening can provide early diagnosis of this group of diseases. The main characteristics are: acute coma /ataxia/encephalopathy with no evidence of encephalitis, acute, prolonged deterioration without cause or nonspecific infectious disease with prolonged duration; symptoms of progressive neurological disease with no diagnosis; 
multi-systemic disease with no diagnosis; acidosis, hypoglycemia and ketonuria in neonates, while organs such as the liver and kidneys may or may not be involved. Diseases of amino acid metabolism may present at any age, but are generally not symptomatic at birth or during the first days of life. Diseases with acute presentation are generally expressed during times of protein catabolism, for example, during the neonatal period (metabolic transition, delays in the food supply), later childhood (changing to protein-rich meals at greater intervals; common infections involving fever, vomiting and reduced food intake) or puberty (changes in growth rate, psychological factors). ${ }^{14}$

The basic principles of treatment vary depending on the pathology and its duration of manifestation (acute or chronic). In diseases with acute presentation, the increase in the breakdown of proteins during catabolic states (fasting, infection, vaccination, surgery) can cause large accumulations of toxic metabolites in short periods of time, leading to severe damage to the cerebral nervous system or death. In these diseases it is imperative to interrupt the catabolic state during initial stage of acute decompensation. Management of this phase is similar to that of the organic acidemias.

Long-term treatment:

1) Diet: protein restriction plus a semi-synthetic amino acid supplement which does not contain amino acids whose breakdown is blocked; supplementation with minerals and microelements. Care must be taken to avoid protein deficiency as a result of "overtreatment" since it may cause protein catabolism, which can be monitored by means of the quantitative analysis of plasma amino acids;

2) Specific vitamins or cofactors (if indicated);

3) Regular monitoring of growth: weight, height, head circumference, psychomotor development;

4) Maintain regular laboratory control of patients on proteinrestricted diets (the metabolic parameters will depend on the disease): full blood test, calcium, phosphorous, magnesium, iron, liver and kidney function tests, alkaline phosphatase, total protein, albumin, prealbumin, cholesterol, triglycerides, vitamins, acid-base balance, ammonia, lactate and plasma amino acids.

\section{Treatment of Iysosomal and peroxisomal diseases}

Lysosomes and peroxisomes are cytoplasmatic organelles contained within their own membranes and with no DNA or ribosomes. They are present in all eukaryotic cells, and peroxisomes are especially abundant in the liver. ${ }^{15,16}$ They perform highly distinct functions in human metabolism. Lysosomes are primarily involved in breaking down macromolecules, such as glycosaminoglycans and sphingolipids, while peroxisomes are primarily involved in the formation of plasmalogens (the most abundant class of myelin phospholipids) and in oxidative reactions associated with breaking down fatty acids ( $\mathrm{B}$ or $\alpha$-oxidation). ${ }^{15,16}$ The oxidation of fatty acids that takes place in peroxisomes exhibits certain differences in relation to the oxidation these substances undergo in the mitochondria: one of the main differences is that the peroxisomal system is more active in oxidation of very long-chain fatty acids (such as hexacosanoic acid) and branched chain fatty acids (such as phytanic and pristanic acids), which derive from the fat of ruminant animals, meat and fish. ${ }^{15,16}$

The majority of lysosomal diseases are caused by the presence of pathogenic mutations to genes that code for enzymes that act within lysosomes (acidic hydrolases), whereas the majority of peroxisomal diseases are caused by mutations to genes that code for proteins involved in the transport of target substances (substrates of peroxisomal enzymes) into the interior of peroxisomes, or which code for proteins involved in directing peroxisomal proteins to the peroxisome (known as "peroxins") (Table 4). Both peroxisomal proteins and lysosomal enzymes are synthesized in the rough endoplasmic reticulum and have markers (signal sequences) that allow them to be directed to the peroxisomes (in a process that is dependent on the "peroxins") or the lysosome (the signal sequence in this case consists of residues of mannose 6-phosphate acquired post- translation), respectively. Some lysosomal enzymes can be secreted and taken in by other cells, which is the phenomenon that provides the basis for one of the treatment strategies for this group of diseases: enzyme replacement therapy (ERT).

The clinical manifestations of lysosomal and peroxisomal diseases are, therefore, highly varied, although generally of a chronic and progressive character. It can be said that, in the case of lysosomal diseases, they are the result of a substrate that is present in higher quantities than normal (i.e., "accumulated " within lysosomes) (Figure 3); in the case of the peroxisomal diseases, the clinical manifestations appear to result both from excess non-degraded substrates (see X-linked adrenoleukodystrophy, Table 4) and from missing products (see peroxisome biogenesis disorders, Table 4). Lysosomal diseases, therefore, are generally associated with morphological phenotypes classically known as "storage" or "accumulation", producing organomegalias and characteristic facies, and neurological phenotypes characterized by presence or absence of regression, whereas peroxisomal diseases can be associated with dysmorphias and malformations (the facial phenotype of Zellweger syndrome, for example, is said to be similar to that of Down Syndrome) and generally provoke neurological regression (Table 4).

\section{Treatment strategies}

It is not the aim of this article to discuss each of the evidential bases for the specific therapies used to treat lysosomal and peroxisomal diseases. What should be made clear is that both groups are made up of rare diseases and there are often no randomized clinical trials comparing placebos with 
Table 4 - Peroxisomal diseases and available treatments ${ }^{17,18}$

\begin{tabular}{|c|c|c|c|}
\hline Disease & Biochemical defects & Clinical features & Treatment \\
\hline $\begin{array}{l}\text { The Zellweger syndrome } \\
\text { spectrum (Zellweger } \\
\text { syndrome, neonatal } \\
\text { adrenoleukodystrophy, } \\
\text { infantile Refsum disease) }\end{array}$ & $\begin{array}{l}\text { Peroxisome biogenesis disorders } \\
\text { ( } 68 \% \text { of the patients with } \\
\text { Zellweger syndrome have } \\
\text { mutations to the PEX } 1 \text { gene, } \\
\text { which codes peroxin } 1 \text { ) }\end{array}$ & $\begin{array}{l}\text { Central hypotonia, convulsions, } \\
\text { high fontanel, punctate } \\
\text { calcifications of epiphyses, } \\
\text { hepatic cysts, adrenal } \\
\text { insufficiency }\end{array}$ & $\begin{array}{l}\text { - Basically symptomatic } \\
\text { - Reduce intake of phytanic acid } \\
\text { - Supplementation with } \\
\text { plasmalogens }\end{array}$ \\
\hline $\begin{array}{l}\text { Rhizomelic } \\
\text { chondrodysplasia punctata } \\
\text { spectrum (type I or classical, } \\
\text { II and III) }\end{array}$ & $\begin{array}{l}\text { Peroxisome biogenesis disorders } \\
\text { (all patients with the classical } \\
\text { form have mutations to the PEX7 } \\
\text { gene which codes peroxin 7) }\end{array}$ & $\begin{array}{l}\text { Proximal shortening of the } \\
\text { humerus and femur, punctate } \\
\text { calcifications of cartilage, } \\
\text { cataracts, coronal clefts of the } \\
\text { vertebrae, contractures of joints, } \\
\text { mental retardation, convulsions }\end{array}$ & $\begin{array}{l}\text { - Basically symptomatic } \\
\text { - Reduce intake of phytanic acid } \\
\text { - Supplementation with } \\
\text { plasmalogens } \\
\text { - Removal of cataracts } \\
\text { - Physiotherapy }\end{array}$ \\
\hline $\begin{array}{l}\text { X-linked } \\
\text { adrenoleukodystrophy }\end{array}$ & $\begin{array}{l}\text { Deficient transport of very long } \\
\text { chain fatty acids into } \\
\text { peroxisomes, with consequent } \\
\text { increase in their concentration in } \\
\text { plasma and cell interiors }\end{array}$ & $\begin{array}{l}\text { Six clinical phenotypes are } \\
\text { described classically: } \\
\text { 1) childhood cerebral form (the } \\
\text { most common); } \\
\text { 2) the cerebral adolescent form; } \\
\text { 3) adrenomyeloneuropathy ; } \\
\text { 4) adrenocortical insufficiency } \\
\text { alone; } \\
\text { 5) the cerebral adult form; } \\
\text { 6) presymptomatic/ } \\
\text { asymptomatic }\end{array}$ & $\begin{array}{l}\text { - Corticoid replacement if there is } \\
\text { adrenal insufficiency } \\
\text { - Transplant of hematopoietic } \\
\text { stem cells in certain selected } \\
\text { cases (patients in the initial } \\
\text { phases of neurological } \\
\text { involvement) } \\
\text { - Lorenzo's oil and statins, such as } \\
\text { lovastatin, normalize plasma } \\
\text { levels of very long chain fatty } \\
\text { acids }\end{array}$ \\
\hline Refsum disease & $\begin{array}{l}\text { Deficient phytanoyl-CoA } \\
\text { hydroxylase activity in } 90 \% \text { of } \\
\text { patients; the remainder have a } \\
\text { PEX7 mutation }\end{array}$ & $\begin{array}{l}\text { Anosmia, retinitis pigmentosa, } \\
\text { neuropathy, hypoacusia, ataxia, } \\
\text { ichthyosis, cardiac arrhythmia, } \\
\text { cardiomyopathy }\end{array}$ & $\begin{array}{l}\text { - Dietary: hypercaloric diet with } \\
\text { restricted phytanic acid intake - } \\
\text { Symptomatic: moisturizers for } \\
\text { ichthyosis, medication for cardiac } \\
\text { problems }\end{array}$ \\
\hline
\end{tabular}

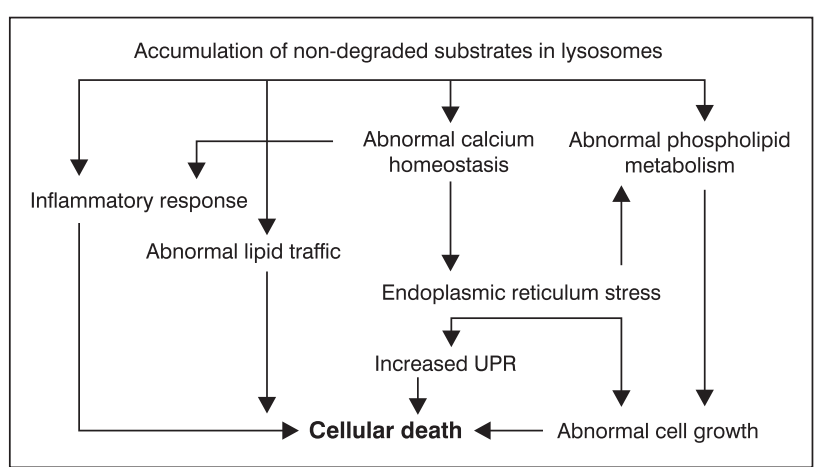

UPR $=$ unfolded protein response.

Figure 3 - Pathophysiology of lysosomal diseases (adapted from Kacher \& Futerman ${ }^{19}$ )

the medications in question. On the other hand, where clinical trials have been carried out, the sample sizes tend to be small as a result of the rarity of the individual conditions themselves. Another point that should be highlighted is that many of the medications used for the treatment of these groups of diseases are, in general, of high cost and not yet included on the Brazilian Ministry of Health's lists of special medications and many have not even been licensed in Brazil yet (which does not prevent them from being used, since they are very often the only treatment options available for a given condition).

The objective here is to describe, succinctly, the main treatment strategies available and to point out that using these innovative treatments will, in some cases, be associated with a certain degree of uncertainty with relation to their safety and efficacy. It is not uncommon for there to be an occasional lack of agreement between specialists, whether with relation to an indication itself or the to dose of medication that should be used. This is why it is recommended that individuals with lysosomal and peroxisomal diseases should be treated at tertiary care centers by professionals who are specialized in their management. Those who are interested in finding out about specific treatment in greater detail are invited to perform at their own literature reviews (one website which offers 
Table 5 - Specific therapeutic strategies available for lysosomal diseases

Strategy Observations

Hematopoietic cell transplantation

ERT

Organ transplantation

Inhibition of substrate synthesis

Depletion of accumulated substrate
- Consider in all patients where diagnosis has been made early, especially those less than 12 months old, since this appears to be the only available therapy which offers the potential of interfering in the natural history of the brain disease.

- There is a basis in the literature for indicating its use in patients with the severe form of MPS I who are aged less than 18-24 months; infants with presymptomatic Krabbe disease; $\alpha$-mannosidase deficiency; patients with late forms of Krabbe disease or metachromatic leukodystrophy. ${ }^{21-23}$

-Available for MPS I, MPS II, MPS VI, Gaucher disease, Fabry disease and Pompe disease. There is no consensus in the literature on the ideal age for starting ERT, nor on treatment indications for all patients.

-Kidney, to treat chronic renal failure (Fabry disease, cystinosis).

- Cornea (MPS, cystinosis).

- Miglustat, indicated for the treatment of adult patients with Gaucher disease who have contraindications to or cannot tolerate ERT with imiglucerase.

- Patterson et al. ${ }^{24}$ demonstrated improvement in substitute outcomes with miglustat compared with placebo in a randomized clinical trial with 29 Niemann-Pick disease type $C$ patients over 12 years old.

- Cysteamine for treatment of cystinosis.

Attenuated form or Scheie syndrome) $=\alpha$-iduronidase deficiency; cystinosis = cystinosin deficiency; ERT = enzyme replacement therapy; fabry disease $=\alpha$-galactosidase A deficiency; Gaucher disease $=\beta$-galactosidase deficiency; intermediate form or Hurler-Scheie syndrome; Krabbe disease (globoid cell leukodystrophy) = galactosylceramidase deficiency; metachromatic leukodystrophy = arylsulfatase A deficiency; MPS = mucopolysaccharidoses; MPS I (severe form or Hurler syndrome; Niemann-Pick disease type C = accumulation of non-esterized cholesterol lysosomes, secondary to mutations in both alleles of the NPC1 gene (more common) or the NPC2 gene; MPS II (Hunter syndrome) = iduronate sulfatase deficiency; MPS VI (Maroteaux-Lamy syndrome $)$ N-acetylgalactosamine 4-sulfatase deficiency; Pompe disease= acid maltase deficiency.

a good level of up-to-date information on treatments for genetic diseases is GeneClinics ${ }^{18}$ ).

We would also point out that there are many ongoing clinical trials investigating lysosomal and peroxisomal diseases (we suggest consulting www.clinicaltrials.gov ${ }^{20}$ run by the United States National Institutes of Health).

\section{Treatment of peroxisomal and lysosomal diseases}

Treatment for the majority of peroxisomal diseases is essentially palliative, involving, in some cases, manipulating the patient's diet (Table 4).

The strategies employed for the treatment of lysosomal diseases include hematopoietic cell transplantation; ERT; transplantation of damaged organs (especially kidneys); the use of substrate synthesis inhibitors; and depletion of accumulated substrates (Table 5). Chaperones (molecules that restore the native configuration of mutant enzymes, thereby increasing their residual activity), cellular therapy and gene therapy are all still experimental.

Enzyme replacement therapy consists of intravenous administration of a recombinant form of the enzyme in which the patient is deficient (Tables 5 and 6). Its greatest limitations are related to the fact that it does not significantly affect progression of bone or neurological disease since brain and bone are relatively inaccessible to "large" molecules such as recombinant enzymes. Studies of different methods of administrating enzymes, such as intrathecal and intraarticular application, are being carried out in the hope of overcoming this obstacle. ${ }^{25,26}$

Substrate synthesis inhibitors are molecules that inhibit enzymes involved in the synthesis of substrates that accumulate in lysosomal diseases, thereby reducing their buildup. Only miglustat (an inhibitor of glucosylceramide synthase, the enzyme responsible for the first step of glycosphingolipid synthesis) has been licensed by both the Food and Drug Administration (FDA) and the European Medicines Agency (EMEA) for use with human beings (Table 5 ). Both substrate synthesis inhibitors and chaperones (promising drugs that are still in development for clinical use) are smaller molecules that can penetrate the blood-brain barrier and potentially have an effect on the central nervous system.

\section{Conclusions}

Few areas of medicine have advanced as much over recent years as treatments for IEM. Even though for many conditions the new treatments do not yet offer a cure, they 
Table 6 - Replacement therapy for lysosomal diseases: summary of available medications

\begin{tabular}{|c|c|c|c|c|c|c|c|c|}
\hline Product & Disease & $\begin{array}{c}\text { Location } \\
\text { where the } \\
\text { recombinant } \\
\text { enzyme is } \\
\text { produced }\end{array}$ & Dose & $\begin{array}{c}\text { Duration } \\
\text { of } \\
\text { infusion* }\end{array}$ & $\begin{array}{c}\text { Need } \\
\text { for premedication }\end{array}$ & $\begin{array}{l}\text { Licensed } \\
\text { by EMEA }\end{array}$ & $\begin{array}{c}\text { Licensed } \\
\text { by FDA }\end{array}$ & $\begin{array}{c}\text { Registered } \\
\text { with } \\
\text { ANVISA }^{+}\end{array}$ \\
\hline Imiglucerase & Gaucher & $\mathrm{CHO}$ cells & $\begin{array}{l}10-60 \mathrm{U} / \mathrm{kg} \\
\text { every } 15 \\
\text { days }\end{array}$ & 2 hours & $\mathrm{No}^{+}$ & Yes & Yes & Yes \\
\hline $\begin{array}{l}\text { Agalsidase } \\
\text { alpha }\end{array}$ & Fabry & $\begin{array}{l}\text { Human } \\
\text { fibroblasts }\end{array}$ & $\begin{array}{l}0.2 \mathrm{mg} / \mathrm{kg} \\
\text { every } 15 \\
\text { days }\end{array}$ & 40 minutes & $\mathrm{No}^{\ddagger}$ & Yes & No & No \\
\hline $\begin{array}{l}\text { Agalsidase } \\
\text { beta }\end{array}$ & Fabry & $\mathrm{CHO}$ cells & $\begin{array}{l}1 \mathrm{mg} / \mathrm{kg} \\
\text { every } 15 \\
\text { days }\end{array}$ & 4-6 hours & Yes & Yes & Yes & Yes \\
\hline Laronidase & MPS I & $\mathrm{CHO}$ cells & $\begin{array}{l}0.58 \\
\mathrm{mg} / \mathrm{kg} \\
\text { once a } \\
\text { week }\end{array}$ & 4 hours & Yes & Yes & Yes & Yes \\
\hline Idursulfase & MPS II & $\begin{array}{l}\text { Human } \\
\text { fibroblasts }\end{array}$ & $\begin{array}{l}0.5 \mathrm{mg} / \mathrm{kg} \\
\text { once a } \\
\text { week }\end{array}$ & 3 hours & $\mathrm{No}^{\neq}$ & Yes & Yes & Yes \\
\hline Galsulfase & MPS VI & $\mathrm{CHO}$ cells & $\begin{array}{l}1 \mathrm{mg} / \mathrm{kg} \\
\text { once a } \\
\text { week }\end{array}$ & 4 hours & Yes & Yes & Yes & No \\
\hline $\begin{array}{l}\text { Alglucosidase } \\
\text { alpha }\end{array}$ & Pompe & $\mathrm{CHO}$ cells & $\begin{array}{l}20 \mathrm{mg} / \mathrm{kg} \\
\text { every } 15 \\
\text { days }\end{array}$ & 4 hours & $\mathrm{No}^{\mp}$ & Yes & Yes & No \\
\hline
\end{tabular}

ANVISA = Agência Nacional de Vigilância Sanitária (National Agency for Sanitary Vigilance); attenuated form or Scheie syndrome) = $\alpha$-iduronidase deficiency; $\mathrm{CHO}=$ Chinese hamster ovary; EMEA = European Medicines Agency; Fabry disease = $\alpha$-galactosidase A deficiency; FDA = Food and Drug Administration; Gaucher disease $=\beta$-galactosidase deficiency ; intermediate form or Hurler-Scheie syndrome; MPS = mucopolysaccharidosis; MPS I (severe form or Hurler syndrome; MPS II (Hunter syndrome) = iduronate sulfatase deficiency; MPS VI (Maroteaux-Lamy syndrome) = $\mathrm{N}$-acetylgalactosamine 4-sulfatase deficiency; Pompe disease = acid maltase deficiency.

* The time given here is the standard infusion time which can be adjusted for specific cases.

+ Data current as of August 2008.

₹ Premedication may be necessary if the patient exhibits a reaction to the infusion.

undoubtedly signify an important step towards improved quality of life and give many patients a chance of surviving while more effective and definitive treatments are developed.

Treating IEM is a complex undertaking that should be carried out by a multidisciplinary team, of which a pediatrician is the key member, but which will also benefit from the presence of a geneticist, neuropediatrician, intensive care specialist and clinical pathologist in addition to other professionals such as a nutritionist, nurse and physiotherapist, to mention some examples.

The development of new treatment methods has made early diagnosis more important, stimulating neonatal screening programs, which in turn result in earlier, more successful, interventions. They also provide evidence that these diseases that are considered to be very rare are in fact little known and little diagnosed, which should change as the treatments that have been described briefly here become available.

\section{References}

1. Leonard JV, Morris AA. Inborn errors of metabolism around time of birth. Lancet. 2000;356:583-7.

2. Touati G, Valayannopoulos V, Mention $K$, de Lonlay $P$, Jouvet $P$, Depondt $E$, et al. Methylmalonic and propionic acidurias: management without or with a few supplements of specific amino acid mixture. J Inherit Metab Dis. 2006;29:288-98.

3. Walter $\mathrm{JH}, \mathrm{MacDonald} \mathrm{A}$. The use of amino acid supplements in inherited metabolic disease. J Inherit Metab Dis. 2006;29: 279-80.

4. Bosch A. Classical galactosaemia revisited. J Inherit Metab Dis. 2006;29:516-25. 
5. Ferenci P. Pathophysiology and clinical features of Wilson disease. Metab Brain Dis. 2004;19:229-39.

6. Walter JH, Wraith JE. Treatment: present status and new trends. In: Fernandes J, Saudubray JM, Van den Berghe G, Walters JH, editors. Inborn metabolic diseases: diagnosis and treatment. 4th ed. Heidelberg: Springer; 2006. p. 83-96.

7. Souza CF, Brum J, Refosco L, Banin M, Kyosen S.Tirosinemia. In: Martins AM, Frangipani B, Micheletti C, Oliveira R. Protocolo brasileiro de dietas: erros inatos do metabolismo. São Paulo: Segmento Farma; 2006. p. 31-9.

8. Prietsch V, de Baulny HO, Saudubary JM. Emergency treatment. In: Fernandes J, Saudubray JM, Van den Berghe G, Walters JH, editors. Inborn metabolic diseases: diagnosis and treatment. 4th ed. Heidelberg: Springer; 2006. p. 73-8.

9. Clarke JT. Treatment. In: Clarke JT, editor. A clinical guide to inherited metabolic diseases. 3rd edition. Cambridge: Cambridge University Press; 2006. p. 297-321.

10. de Baulny HO, Benoist JF, Rigal O, Touati G, Rabier D, Saudubray JM. Methylmalonic and propionic acidaemias: management and outcome. J Inherit Metab Dis. 2005;28: 415-23.

11. Clayton PT. B6-responsive disorders: a model of vitamin dependency. J Inherit Metab Dis. 2006;29:317-26.

12. Nassogne MC, Heron B,Touati G, Rabier D, Saudubray JM. Urea cycle defects: management and outcome. J Inherit Metab Dis. 2005;28:407-14.

13. Stockler S, Hanefeld F, Frahm J. Creatine replacement therapy in guanidinoacetate methyltransferase deficiency, a novel inform error of metabolism. Lancet. 1996;348:789-90.

14. Zschocke J, Hoffmann GF. Vademecum metabolicum. Manual of metabolic paediatrics. 2nd ed. Stuttgart: Schattauer; 2004.

15. Alberts B, Johnson A, Lewis J, Raff M, Roberts K, Walter P, editors. Molecular biology of the cell. 4th ed. New York: Garland Science; 2005.

16. Nelson DL, Cox MM, editors. Lehninger principles of biochemistry. 4th ed. New York: WH Freeman; 2005.

17. Jones $\mathrm{KL}$, editor. Smith's recognizable patterns of human malformation. 6th ed. Philadelphia: Elsevier Saunders; 2006.
18. National Institutes of Health. Gene Clinics. http:// www.geneclinics.org. Access: 31/01/08.

19. Kacher Y, Futerman AH. Genetic diseases of sphingolipid metabolism: pathological mechanisms and therapeutic options. FEBS Lett. 2006;580:5510-7.

20. U.S. National Institutes of Health. Clinical Trials. http:// www.clinicaltrials.gov .

21. Krivit W, Shapiro EG, Peters C, Wagner JE, Cornu G, Kurtzberg J, et al. Hematopoietic stem-cell transplantation in globoid-cell leukodystrophy. N Engl J Med. 1998;338:1119-26.

22. Escolar ML, Poe MD, Provenzale JM, Richards KC, Allison J, Wood $\mathrm{S}$, et al. Transplantation of umbilical-cord blood in babies with infantile Krabbe's disease. N Engl J Med. 2005;352: 2069-81.

23. Beck M. New therapeutic options for lysosomal storage disorders: enzyme replacement, small molecules and gene therapy. Hum Genet. 2007;121:1-22.

24. Patterson MC, Vecchio D, Prady H, Abel L, Wraith JE. Miglustat for treatment of Niemann-Pick $C$ disease: a randomised controlled study. Lancet Neurol. 2007;6:765-72.

25. Auclair D, Hein LK, Hopwood JJ, Byers S. Intra-articular enzyme administration for joint disease in feline mucopolysaccharidosis VI: enzyme dose and interval. Pediatr Res. 2006;59:538-43.

26. Muñoz-Rojas MV, Costa R, Canani SF, Jardim L, Vedolin L, Kakkis $\mathrm{E}$, et al. Intratechal enzyme replacement therapy in a patient with mucopolysaccharidosis type I and symptomatic spinal cord compression. Am J Med Genet. In press 2008.

Correspondence:

Roberto Giugliani

Serviço de Genética Médica, Hospital de Clínicas de Porto

Alegre

Rua Ramiro Barcelos, 2350

CEP 90035-003 - Porto Alegre, RS - Brazil

Tel.: +55 (51) 2101.8011

Fax: +55 (51) 2101.8010

E-mail: rgiugliani@hcpa.ufrgs.br 